\title{
As opções políticas nos meandros das conceções e práticas dos professores
}

\author{
Carla Lacerda
}

Escola Superior de Educação, Instituto Politécnico de Viseu

\begin{abstract}
Resumo
A democratização do ensino em Portugal conta com 40 anos e ao longo destes foram vários os governos constitucionais a tomar posse e a definir linhas de orientação política para a educação. A instabilidade governativa, vivida ao longo destes anos, não permitiu que a educação seguisse um rumo determinado e as diferentes opções, para além de não convergirem, trouxeram implicações graves para as conceções e práticas dos professores, que muitas vezes desacreditados dos resultados, que determinadas políticas educativas trariam, desinvestiam na sua implementação.

$\mathrm{O}$ presente texto pretende trazer à análise esta caracterização da política educativa portuguesa e a sua relação com o campo pessoal dos professores.

Palavras-chave: políticas educativas, reformas educativas, conceções e práticas de professores.
\end{abstract}

\section{As políticas de Estado nacionais com as supranacionais}

A política educativa elabora-se e realiza-se através e sobretudo pelo Estado (Stoer, 2008), falar de política conduz-nos para os campos da análise sobre o Estado e as suas tipologias. Ao revisitar uma obra de 1823, de Mouzinho de Albuquerque conseguimos perceber que passados quase dois séculos algumas das preocupações de alguns continuam a ser também a preocupação de uns tantos. A escrita da obra, num português quase desconhecido, permite-nos uma viagem a tempos passados, a tempos remotos que contraditoriamente também são os tempos atuais. Mouzinho Albuquerque (1823, p.7) refere o seguinte:

“A instrução publica he pois huma divida sagrada dos governos, os povos tem um direito inegavel de exigi-la, e os representantes do povo devem occupar-se da sua organisação, legislar prompta e eficazmente sobre este objecto, e vigiarem que o poder executivo ponha em vigor o que a este respeito for legislado.

Os cidadão poem á disposição do governo sob o titulo de impostos huma certa parte da sua riqueza fructo do seu trabalho industria ou propriedade para que o governo possa com estes meios satisfazer os seus encargos para com a nação. He d'este modo que da massa dos impostos deve ser paga e mantida a força armada destinada a sustentar a independência nacional, deve ser pago o corpo dos juizes de direito que administrarão a justiça aos cidadãos, deve em summa ser satisfeita a extensa e variada divida dos governantes para os governados; divida cuja satisfação he o único objecto do estabelecimento dos governos legítimos, e não usurpadores ou tirânicos.”

Esta breve citação, desta tão remota e atual obra, retrata uma preocupação para com o Estado (ou governo, se quisermos) em representar o seu povo na legitimação da sua governação, distribuição de bens e serviços considerados como bens comuns e necessários ao desenvolvimento de uma sociedade ou de um povo se assim, vertiginosamente lhe quisermos chamar.

O Estado social que surge após a segunda guerra mundial na Europa e que em Portugal dá os seus primeiros passos, após a revolução de abril, sempre foi pensado, desejado e se quisermos sempre foi projetado no plano da concretização real.

O Estado social, ou Estado providência, que se desenvolveu no século XIX estabeleceu-se com o princípio de redistribuir por todos, independentemente do seu estatuto social, cultural e condição económico financeira, os bens essenciais, como o direito à saúde, à justiça, à segurança e à educação. Através de um pacto social e fiscal, as classes, em função dos seus rendimentos, contribuíam com um imposto progressivo para o Estado, e este por sua vez redistribuía de forma igual e equitativa, por todos os cidadãos, uma série de prestações sanitárias, educativas e socais.

Este Estado social, para além de outras obrigações, tinha também por determinação oferecer uma educação a todos os indivíduos, manifestando-se esta de formas diferentes em função das opções políticas dos países onde foi implementado.

A expansão da educação escolar vai assim tornar-se um investimento social de primeira importância em todo o mundo e o Estado português, após a revolução de abril, percebeu que não haveria desenvolvimento económico sem recursos humanos qualificados pelo sistema escolar. A produtividade do trabalho evoluiria à medida que evoluiria a qualificação profissional inicial dos recursos humanos das empresas (Azevedo, 2007).

Este princípio, há muito defendido por Paulo Freire (1992), de que a educação não é uma alavanca da transformação social, mas sem ela a sociedade não evolui, permite-nos perceber que a tendência do investimento do Estado português era para que a educação pudesse apoiar a transformação social que se ambicionava.

Teodoro \& Aníbal (2007), ao estudarem o estado da educação em Portugal e ao situarem a Reforma Veiga Simão como promotora da educação na assunção de um lugar central na recomposição do Estado, referem que é com a revolução de abril que os problemas educativos ganham um novo espaço político, tornando-se num campo privilegiado de legitimação de uma nova democracia.

"No campo específico das políticas de educação, a revolução permitiu uma nova centralidade para os problemas educativos, remobilizando as aspirações de acesso aos diferentes níveis de escolarização, 
amplificado no início dos anos 70 pelo discurso meritocrático do último ministro da educação do Estado Novo, e abrindo novas frentes nos planos da participação na gestão escolar e na reformulação das estruturas e conteúdos de ensino. A educação, nesse período de crise revolucionária, para além de um aceso palco de lutas políticas, tornou-se um campo privilegiado de legitimação da nova situação democrática, apostada em mostrar uma radical mudança face às anteriores políticas obscurantistas do Estado Novo.” (Teodoro \& Aníbal, 2007, p.16-17).

A reforma Veiga Simão, consumada pela Lei n. ${ }^{0}$ 5/73, de 25 de Julho, deu início à educação democratizante. Ainda não tínhamos assistido à revolução de abril para percebermos que a educação dava os seus primeiros passos para a democratização do ensino. Naturalmente que a revolução de abril foi um dos marcos mais significativos para essa democratização, por ela própria representar esses ideais de liberalização e democratização. Portugal trilhava os primeiros passos do que seria viver numa sociedade mais plural, mais liberal e também ela, numa primeira tentativa, de se transformar numa sociedade mais democrática.

Os primeiros anos que se sucederam ao 25 de abril foram anos de conturbação política e na educação ainda se considerou a continuidade dos princípios da reforma iniciada em 1973, mas cedo se compreendeu que Portugal iria tomar um novo rumo com a economia direcionada para o espaço europeu.

Em 1976, Portugal redefinia o seu papel com a Europa e esta viria a influenciar as políticas nacionais. Acreditava-se, como ainda hoje se acredita, embora se faça pouco para sustentar esta premissa, que a sociedade seria tão mais desenvolvida quanto o fosse a educação. A sociedade portuguesa necessitava urgentemente de se reerguer e a superação dos seus problemas passava efetivamente pela integração na Europa. Portugal ao assumir a integração na Europa comunitária, assumiu-a como um motor exógeno de desenvolvimento do país, cujo discurso sobre a educação se centrou na qualificação da mão-de-obra necessária para a requalificação da economia (Teodoro \& Aníbal, 2007).

Este pressuposto, de a educação ser a panaceia da reestruturação da economia, não é verificável apenas nesta altura. Vários investigadores deram-nos conta disso, bem como, do facto de a nível mundial existir um movimento de reconstrução dos sistemas escolares, nos finais da guerra fria. Pedró \& Puig (1998) referem, a exemplo disso, que na Europa ocidental, e no final da segunda guerra mundial, teve-se a consciência de que se deveria usar a escola para a reconstrução social do sistema político democrático e também usar a escola, na qualificação da mão-de-obra para a reconstrução da economia, muitas vezes debaixo da batuta do Plano Marshall dos Estados Unidos. Popkewitz (2011) também nos refere que as políticas educacionais dos países membros da União Europeia adotaram reformas educativas e curriculares com uma identidade formada em torno das paredes do Tratado de Maastricht que exclui um sentido amplo da Europa, mesmo quando procura inclusões. E ainda a este propósito, Afonso (2002) considera que à expansão capitalista, que se seguiu à II Guerra Mundial, pelas tensões que se viveram entre o capital e o trabalho, o capitalismo e a democracia, a legitimação e a acumulação, a resposta foi a da instauração do Estado providência.

O Estado ficaria assim com a responsabilidade de proteger os interesses dos cidadãos nos mais diferentes campos de necessidades básicas como proteção social, segurança, saúde e educação. Esta relação, de por um lado o Estado ter de proteger os cidadãos dessas necessidades básicas, e por outro de se assumir com intervenção económica, conduziu-o a conflitos difíceis de gerir. A estes conflitos florescem imediatamente as críticas da nova direita (neoliberalismo económico e neoconservadorismo político), que na opinião de Afonso (2002) reclamam uma redefinição do papel e da função do Estado. Os seus pressupostos e críticas ao Estado providência assentam nas considerações de que os indivíduos conhecem/sabem melhor do que o Estado o que é melhor para eles. O mercado, enquanto espécie de organização, é quem melhor pode distribuir, de forma mais justa e equitativa, os bens e serviços, até aqueles que durante décadas estiveram sob a alçada e responsabilidade do Estado, fazendo crer, também, que a desigualdade entre os indivíduos, bem como o acesso a determinados bens, é sempre desigual e diferenciado, por ser uma característica natural da sociedade.

A par da ideologia de Estado social, muito sustentada pelas teorias Keynesianas surge um movimento de reação contrário que tivera o seu apogeu em meados das décadas de 70 , e particularmente na década de 80 . O movimento neoliberal, que viria a revolucionar e a influenciar as governações dos Estados a nível mundial e que tinham tido a oportunidade de ensaiar o Keynesianismo, passou a tomar corpo num vazio deixado pela nova crise do capitalismo e pela derrocada do socialismo real.

As reformulações das relações do poder impõem novas interpretações da presença do Estado na escolarização, que opta ao longo dos anos, por investir na educação, enquanto forma de promover o desenvolvimento da economia, a reanimação cultural e o desenvolvimento individual (Popkewitz, 1994).

De facto, a integração de Portugal em 1986 na Comunidade Económica Europeia, depois apelidada de União Europeia, viria a influenciar as políticas educativas, agora direcionadas para um espaço de características contextuais indefinidas, mas cujos discursos dos Estados membros, sustentavam um conceito de educação intimamente ligado ao mundo da economia e do trabalho (Teodoro \& Aníbal, 2007). Esta relação viria naturalmente a influenciar os caminhos que a educação viria a trilhar, rompendo, pelo menos ao nível dos discursos, com paradigmas academicistas, tecnicistas e sequencialistas.

Esta integração de Portugal na união europeia traria consigo uma consonância imediata nos discursos políticos e económicos, arrastando-se aos domínios culturais e educacionais. As reformas e as mudanças dos outros países da Europa passaram a ser inspiradoras para Portugal que tentou coadjuvar-se aos mesmos princípios e às mesmas aspirações. Se por um lado se assistia a discursos de contextualização, de territorialização, de 
flexibilidade perante as diferenças nacionais, por outro os discursos internacionais permeabilizavam modelos que inspiravam as decisões políticas, económicas, culturais e educacionais.

Lima \& Afonso (2002) dão-nos conta que independentemente dos Estados-nação serem ideologicamente diversos com programas políticos próprios verifica-se uma “( $\cdots)$ sincronia das reformas, uma forte similitude entre alguns eixos estruturantes e estratégias adoptadas, e até mesmo uma consonância argumentativa quanto aos imperativos das mudanças na educação" (p.7).

Estávamos assim influenciados por forças externas que serviam de referência e de modelo para eventuais reformas a concretizar em Portugal.

\section{As reformas educativas}

As reformas educativas são expressões privilegiadas de projectos políticos e um dos seus principais instrumentos. Com frequência, ou não, as reformas educativas incorporam elementos de inovação que afectam os processos de ensino e aprendizagem e os conteúdos curriculares (Pedró \& Puig, 1998). Mas se os conceitos de reforma e inovação, no campo educativo, se associam pelo menos em teoria, na prática os mesmos podem ser contraditórios. Na opinião de Pedró \& Puig (1998), as reformas educativas muitas vezes parecem centrar-se nos interesses dos políticos em colocar nas suas agendas reformas estruturais e não tanto em as levar a cabo. Postulam-se princípios, metas e finalidades a atingir e esquecem-se os processos instrumentais para levar a cabo tais propósitos. Os diferentes programas de diferentes governos constitucionais são bem exemplo disso, ao surgirem com as mesmas medidas, de forma consecutiva, ao longo de vários anos.

Segundo estes autores a inovação educativa pode incluir uma ou várias das dimensões seguintes no contexto educativo:

- a introdução de novas áreas ou conteúdos curriculares;

- a utilização de novos materiais e tecnologias curriculares;

- a aplicação de novas abordagens e estratégias dos processos de ensino e aprendizagem;

- a mudança das crenças e pressupostos pedagógicos dos diferentes atores educativos.

Não queremos aqui analisar de forma detalhada cada um destes campos na sua relação com as políticas educativas firmadas em Portugal, mas de forma sumária podemos referir que todas estas dimensões marcaram presença nos palcos das diferentes governações. As crenças e os pressupostos pedagógicos dos diferentes atores educativos é o mais difícil de confirmar, talvez também o mais difícil de mudar.

Podemos neste caso constatar que as mudanças efetivas ocorrem quando as mesmas produzem efeitos positivos ou negativos no campo em que estão a operar. Se a alteração é apenas superficial ou corresponde à produção de documentos cujo efeito prático é nulo ou quase inexistente e se a mudança não corresponde a algo novo nas práticas ou pressupostos pedagógicos dos diferentes agentes educativos, estamos perante algo que dificilmente altera o status quo instalado.

Como referia Bolívar (2007), o que tem de mudar não se pode prescrever, porque as mudanças dependem do que pensam os professores, de como as interpretam e põem em prática. Portanto não é possível pensar e promover de forma gerencialista qualquer reforma, aliás ela pode fazer-se mas não pode projetar resultados reais que porventura ambiciona.

\section{O campo pessoal da mudança}

Para que possamos ter nas escolas mudanças substantivas é importante que a aliança se faça entre as mudanças externas, internas e pessoais. Sabe-se que são os professores em última instância, a por em prática as mudanças que permitem a sustentabilidade que Goodson (2008), Hargreaves \& Fink (2000) referem. Qualquer mudança que se deseja implementar é importante que a mesma vá ao encontro dos desejos, das expectativas, das motivações e ideais dos professores.

Por isso é importante dar à mudança pessoal um papel primordial na análise da mudança educacional. As teorias sobre mudanças procuram saber como as pessoas mudam essas instituições, contudo e na opinião de Goodson (2008) o importante é compreender como as pessoas mudam internamente e como aquela mudança pessoal pode influenciar ou determinar uma mudança institucional.

É possível percebermos que as mudanças traçadas pelo poder político não conseguirão ter sucesso se as mesmas não forem capazes de captar o interesse, a motivação dos professores no seu envolvimento para com elas. Esta perspectiva, aqui analisada, permite-nos compreender o quanto é relevante o envolvimento dos professores nas mudanças que se esperam fazer sentir nas escolas. Mas se aos professores cabe, em última instância, fazer acontecer a mudança das práticas é também de considerar que as mesmas têm de ser delineadas, pensadas por uma instância superior. Sabe-se, e pelas características circunscritas ao nosso sistema educativo, que o poder político tem determinado o caminho que a educação deve assumir. Foram vários os anos a criar aquilo a que nós hoje chamamos de escola democrática e por mais que se apele à mudança, a verdade é que a mesma tem sido uma realidade pouco inteligível.

Independentemente dos anos em que nos possamos situar sobre a literatura referente à educação é curioso que os discursos apontam para evidências educativas que nem sempre estiveram de acordo com os propósitos, objectivos pretendidos, há sempre um certo resquício para algo que se devia fazer dentro de um contexto que se caracteriza com todo o cuidado. Apela-se a determinações, a cuidados a ter em conta, a modelos a seguir, a opções a tomar, mas na verdade e passados tantos anos consegue-se compreender que nem tudo permanece inalterado e que efectivamente algo mudou na educação portuguesa. Talvez tenhamos de tomar em consideração o sentido ou a natureza da mudança e a forma como as mesmas podem ser mais efetivas e sustentáveis no desenvolvimento de melhorias das práticas das escolas. 
Se a análise se deve centrar nas medidas planeadas ou nas medidas implementadas ou sentidas e concretizadas pelos professores é algo que nos parece ser indissociável. Sabemos no entanto que esta relação tem de existir. Nenhuma mudança se pratica sem que os professores a ponham em prática e embora esta seja uma condição, a mesma parece não ter sido sempre assim equacionada.

\section{As opções políticas dos diferentes governos constitucionais}

Após uma detalhada análise aos dezanove programas dos governos constitucionais conseguimos perceber que medidas ocorreram ao longo destes últimos 40 anos de democracia. De acordo com Pedro \& Puig (1998), conseguimos compreender que as mesmas centraram-se nas diferentes dimensões de mudança - de alteração de conteúdos a ensinar, da introdução de novos métodos e tecnologias, de novas estratégias pedagógicas e de alterações das conceções e pressupostos pedagógicos.

A tabela abaixo sintetiza algumas das medidas mais relevantes. Aquelas que do nosso ponto de vista mais mudança provocaram na escola.

Tabela 1.

Principais medidas dos diferentes governos constitucionais (1976 - 2015)

\begin{tabular}{|c|c|}
\hline $\begin{array}{l}\text { Governos } \\
\text { Constitucionais }\end{array}$ & Principais medidas \\
\hline $\begin{array}{l}\text { I Governo - } \\
\text { XIX Governo } \\
\text { (8 anos) }\end{array}$ & sem medidas implementadas \\
\hline $\begin{array}{l}\text { X Governo } \\
\text { (20 meses) }\end{array}$ & $\begin{array}{l}\text { lei de bases do sistema educativo, identidade } \\
\text { educativa, modernização, igualdade de } \\
\text { oportunidades }\end{array}$ \\
\hline $\begin{array}{l}\text { XI Governo } \\
\text { ( } 37 \text { meses) }\end{array}$ & reforma educativa, autonomia de escolas \\
\hline $\begin{array}{l}\text { XII Governo } \\
\text { (47 meses) }\end{array}$ & $\begin{array}{l}\text { pluralismo, prova geral de acesso ao ensino } \\
\text { superior (PGA), propinas no ensino superior }\end{array}$ \\
\hline $\begin{array}{l}\text { XIII Governo } \\
\text { (47 meses) }\end{array}$ & $\begin{array}{l}\text { pacto educativo, parcerias, acordos, } \\
\text { negociação, autonomia (escolas e } \\
\text { professores), flexibilização curricular, } \\
\text { comunidade educativa, inclusão, territórios } \\
\text { educativos de intervenção prioritária }\end{array}$ \\
\hline $\begin{array}{l}\text { XIV Governo } \\
(29 \text { meses) }\end{array}$ & projetos curriculares de escola e de turma \\
\hline $\begin{array}{l}\text { XV Governo } \\
\text { (26 meses) }\end{array}$ & $\begin{array}{l}\text { rankings, liberdade de escolha, meritocracia } \\
\text { (contra a escola igualitária), avaliação }\end{array}$ \\
\hline $\begin{array}{l}\text { XVI Governo } \\
\text { (8 meses) }\end{array}$ & externa \\
\hline $\begin{array}{l}\text { XVII Governo } \\
\text { (47meses) }\end{array}$ & $\begin{array}{l}\text { avaliação externa, resultados, controlo social } \\
\text { (trabalho do professor), avaliação dos }\end{array}$ \\
\hline $\begin{array}{l}\text { XVIII Governo } \\
\text { (47 meses) }\end{array}$ & $\begin{array}{l}\text { professores, autoridade, hierarquia entre } \\
\text { professores, qualidade (da escola pública), } \\
\text { ensino do inglês no } 1 .^{\circ} \text { ciclo do ensino básico }\end{array}$ \\
\hline $\begin{array}{l}\text { XIX Governo } \\
\text { (2011- até ao } \\
\text { presente) }\end{array}$ & $\begin{array}{l}\text { exames, retorno à pedagogia por objetivos, } \\
\text { avaliação de professores, estandardização de } \\
\text { indicadores de resultados nacionais com os } \\
\text { supranacionais, privilégio das disciplinas } \\
\text { estruturantes }\end{array}$ \\
\hline
\end{tabular}

Conseguimos compreender a partir da tabela que as medidas efectivadas ao longo dos 19 governos constitucionais nem sempre convergiram nos mesmos propósitos. A instabilidade política não permitiu que se efectivassem mais cedo algumas das medidas já anunciadas no programa do I governo constitucional, como por exemplo, a aprovação de uma lei de bases do sistema educativo que permitisse estabelecer as normas e princípios de organização e funcionamento da educação em Portugal.

A ausência de avaliações às políticas educativas em Portugal não nos permitiu também perceber o alcance de outras medidas anunciadas nos diferentes programas de governo mas não alcançadas ou então não visíveis nos terrenos das escolas, sendo estas as que mais projeção tiveram nas escolas e nos professores.

\section{Algumas conclusões}

Tendencialmente as investigações sobre mudanças e reformas educativas têm direcionado o seu sucesso efectivo, no que à melhoria das aprendizagens diz respeito, para as emoções dos professores. A dimensão emocional do ofício de ensinar (Bolívar, 2007) tem conduzido a investigação para o entendimento do que leva os professores a se dedicarem, naquilo que motiva os professores a dar o seu melhor. Ao se valorizar a dimensão emocional do desempenho profissional do professor, no sentido de compreender o modo como o professor se entusiasma e se apaixona com o saber que partilha com os seus alunos, está a estabelecer-se uma relação entre esse entusiasmo e o modo como podem as mudanças educativas, isto é, as reformas se relacionar com esse lado emocional. Ora, neste caso, acredita-se que é importante considerar a identidade que cada professor constrói na sua profissão.

Julgámos que não estamos a desprestigiar a tendência das investigações ao reconhecermos que para alguns professores o seu bom desempenho profissional é independente de qualquer mudança e/ou reforma educativa que se queira implementar, já que a sua finalidade é, essencialmente, a aprendizagem real de todos os seus alunos, sendo os seus esforços canalizados para esses fins, que alguns poderão considerar utópicos, mas que para muitos só faz sentido serem assim no quadro da sua missão, se os alunos alcançarem o sucesso a que têm direito.

O que gostaríamos ainda de aqui deixar registado é que estamos crentes que alguns professores alteram e mudam as suas práticas se, no quadro do seu desempenho profissional, o mais importante for a aprendizagem dos alunos. Esses professores alteram as suas práticas independentemente das reformas que ocorram, das mudanças que se enunciem. Neste quadro de ideias a análise que aqui se está a traçar reporta-nos para a compreensão dos desempenhos profissionais dos professores e na forma como constroem a sua identidade profissional.

A dualidade dos discursos científicos e normativos nem sempre convergem nos mesmos propósitos. E se por vezes os preâmbulos parecem antever a execução de uma política há muito reivindicada por investigadores, nem 
sempre as suas propostas de execução são consentâneas com o que se espera que aconteça.

Chama-se vezes sem conta as escolas e os professores para a responsabilização e o comprometimento no desenvolvimento das aprendizagens de todos os alunos. Fala-se na necessidade dos professores fazerem uma série de lutos, de os professores serem capazes de olhar para os alunos como sendo diferentes nos seus status, na sua linguagem, nas suas capacidades, nas suas competências, nos seus interesses, nas suas motivações e expectativas, de serem capazes de lidar com essas diferenças não como um entrave ou dificuldade mas antes como um desafio. Mas se este discurso é muitas vezes apregoado, o mesmo não pode ser descontextualizado das políticas que o vão sustentando e que podem inibir, desmotivar ou até confundir o rumo que se espera que os diferentes intervenientes no campo educativo, assumam.

O que estamos a tentar relacionar é que as conceções dos professores e as suas práticas não podem ser descontextualizadas de políticas educativas que ao longo de décadas se vêm enunciando e anunciando e que colocam o papel do professor em planos cuja centralidade da sua função é talvez a mais proliferada e vasta no seu campo.

Embora tenhamos tido ao longos dos últimos 40 anos uma instabilidade governativa essa não contribuiu favoravelmente para uma acalmia nos rumos e propósitos para a educação. Também as mudanças bipolares para apenas duas forças políticas conduziram-nos para uma escassa (ou inexistente) avaliação de políticas educativas, bem como para uma certa destruição das políticas, anteriormente levadas a cabo, pela força política que entretanto deixou de figurar no Governo. Esta certa desresponsabilização pelo cumprimento de certas medidas, que se tentaram levar a cabo, não permitiram que as mesmas hoje se possam avaliar de uma forma séria, pois que as mesmas não tiveram o tempo de maturação necessário.

\section{Referências}

Afonso, A. (2002). "Políticas contemporâneas e avaliação educacional”. In Lima, Licínio \& Afonso,
Almerimdo (2002). Reformas da Educação Pública Democratização, Modernização, Neoliberalismo.

Porto: Edicões Afrontamento.

Azevedo, J. (2007). Sistema Educativo Mundial ensaios sobre a regulação transnacional da educação. Vila Nova de Gaia: Fundação Manuel Leão.

Bolívar, A. (2007). "Um olhar atual sobre a mudança educativa: onde situar os esforços de melhoria?”. In Leite, Carlinda \& Lopes, Amélia (2007). Escola, Currículo e Formação de Identidades. Porto: Edições Asa.

Freire, P. (1991). A Educação na Cidade. São Paulo: Cortez Editora.

Goodson, I. (2008). Conhecimento e Vida Profissional estudos sobre educação e mudança. Porto: Porto Editora.

Hargreaves, A. \& Fink, D. (2007). Liderança Sustentável. Porto: Porto Editora.

Lima, L. \& Afonso, A. (2002). Reformas da Educação Pública - Democratização, Modernização, Neoliberalismo. Porto: Edições Afrontamento.

Mouzinho de Albuquerque, L. (1823). Ideas sobre o estabelecimento da instruç̧ão publica. Paris: Academia das Ciencias de Paris.

Pedró, F. \& Puig, I. (1998). Las Reformas Educativas Una perspectiva política y comparada. Barcelona: Paidós.

Popkewitz, T. (1994). Sociología política de las reformas educativas. Madrid: Edições Morata

Popkewitz, Thomas (2011). Políticas Educativas $e$ Curriculares - Abordagens Sociológicas Críticas. Mangualde: Edições Pedago.

Stoer, S. (2008). O Estado e as políticas educativas: Uma proposta de mandato renovado para a Escola Democrática. In Educação, Sociedade \& Culturas, $n .^{\circ}$ 26, 2008, 149-173, disponível

em http://www.fpce.up.pt/ciie/revistaesc/ESC26/26-O Estado.pdf

Teodoro, António \& Aníbal, Graça (2007). A Educação em tempos de globalização: modernização $e$ hibridismo nas políticas educativas em Portugal. Disponível em http://www.scielo.oces.mctes.pt/pdf/rle/n10/n10a0 2.pdf 